A second diagram explains this simply. Here a portion of ocean is divided into numbered squares of 25 feet, and the advance of the $25^{\prime}$ luminous waves, $75^{\prime}$ apart is shown in two following positions. It will be seen that spaces numbered 4 and 13 fall successively under the impulses. Similarly, in the next $25^{\prime}$ advance of the waves, would all those numbered 12 and 15 , and so on, the assumed dark spaces following in the wake of each intersection, as it pursues its diagonal course.

Beckenham, August 5

EDWARd H. PRINGLE

\section{The Planet Jupiter}

IN the bright zone south of the south equatorial belt may now be seen a strange and beautiful feature like a flame--red elliptical cloud surrominded by a brilliant white aureole. I first observed it near midnight on the $14^{\text {th }}$ inst., when approaching the middle of its apparent course across the disk.
In November, I869, Mr. Gledhill discovered an elliptical figture in the same zone, but it was dark, with an interior space bright and colourless.

Gledhill's No. 2 belt (Ast. Register, A pril, 1870), which was a most striking feature for some years, disappeared in 1874 , reappeared in May, 1875, again disappeared, and is now again faintly visible. It is under (north of) the north equatorial belt.

The south equatorial belt seems of a slate-blue, the north of a russet or dark red colour. The bright central space is crossed by dark, irregular bridges slanting from south-west to north-eastthe invariable direction of all the oblique formations that I have ever remarked on Jupiter.

The north polar region seems occupied by a number of apparently close, narrow belts. The south has a pretty similas appearance, but the belts here are not so numerous nor so distinct.

August I 5

\section{Twenty-nine Gleams of Sunshine, August $7,8,9$, in} Nine Hours

IN a paper, about weather, written by Mr. Ellis, of Greenwich Observatory, and published in NATURE, vol, xx. p. 3I3, mention is made of work done with an instrument for registering sunshine, which I contrived, got made, and gave to the Observatory. It consists of a glass sphere, a stand for it, and a metal bowl. The spherical surfaces have a common centre, and radii so measured that the focal cone of sunshine condensed by the glass is cut, by blackened cardboard fixed in the bowl, at the same distance, and at right angles, whatever the sun's position may be in the visible sky. The temperattre near the point is at least $700^{\circ}$ when the weather is clear. The sun's circular image describes a circle about the common centre, and it burns a trace on cardboard when the sun shines clearly. I can think of nothing better or simpler for the purpose of registering sunshine and counting clouds daily.

The inclosed printer's block was engraved in the focal cone of a cast glass sphere. The flat surface, blackened with shoe- blacking, was set roughly parallel to the plane cf the equator, and the hot point was brought to bear upon it, at about I P.M. on August 7. Thus arranged the section of the cone is not circular, but is an ellipse, which is longer or shorter in proportion to the clearness of the atmosphere. The ellipse describes a circle on the boxwood plane. Hollows burned out by it print white, the surface left prints black. Clouds which crossed the sun's path may be counted between white oval spots. There are twenty-nine spots, the rest was clond. In common weather parlance the morning of the 7 th was "sunny," but the blue sky was veiled by a broken roof of thin detached clouds, moving eastward. They hindered heat waves. Between them were narrow clearer openings. When one of these passed the sun the cone of sunshine burned the block instantly. Afternoon about two, the broken cloud roof mended, rain fell, and the evening was dark and sunless. The night was wet. The morning of the 8th was "cloudy." Not a patch of blue sky was visible big enough to make a pair of breeches for a Dutchman. But the weather "looked as if it might clear up." The sun was "trying to shine." Birds sung notes which forecast a fine day,

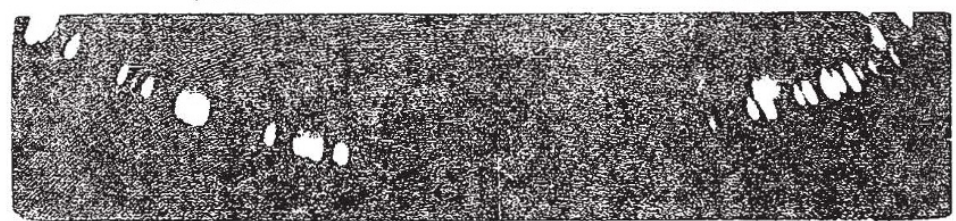

and the day was "fine." The official foresast was "cloudy" and the day was very clouly. The sun was seen "wading through mist" at intervals. At 10 A.M. one brighter gleam burned a mark; but that was all the bright sunshine that reached this garden. For a great depth the air was full of water condensed into the shape of the burning glass. Each spherical drop acted on sunshine as the bulb of a spirit thermometer acts-in "absorbing heat," in stopping, refracting, and dispersing waves of solar radiation. There was more shade than sunshine at the ground. The morsing of the $9^{\text {th }}$ was sumny, hazy, and cloudy. But large patches of very pale blue sky were visible. Birds foretold a fine day, and they were true prophets. The sun's imare came on the block at 9.30 A.M., and it was set carefully at IO, and left till 2 P.M. The air was "thick" all day, the blue of the sky was very pale, and the sunshine "watery." The record shows when brighter gleams occurred during the time of exposure. About noon, as commonly happens, clouds gathered and hid the stn. The brightest time came after noon.

This bit of "thernographic wood engraving" may give readers in brighter climes some notion of the dismal cloudy sky of this abnormal English stmmer. There has not been a cloudless day since the year began. The blue of the sky never has been the dark indigo of Egyptian and Californian skies.

The cause of this excess of cloud I take to be excess of solar radiation and consequent evaporation to our westward. Condensation has been in proportion along the European Atlantic coasts, where the ground was chilled by a late and severe winter, and has been little warmed and dried since by sunshine. According to casual and official weather reports, public and private, the heat has bccn great in America, on the Atlantic, in Spain, in the south of France, in Eastern Russia, in Egypt, and on the
Red Sea. The sun shines fiercely upon the ground beyond the edge of a great cloud which has come persistently from the Western Ocean to overshadow our islands, and to drench and batter them with rain and hailstones. Our shadow is the result of sunshine. Our grass is green, our health is good, our gardens are gay in spite of the clouds, or because of them.

Believing in this theory I am going eastward in search of brighter weather, and I send this record of watery sunshine for your acceptance before I start.

Niddry Lodge, Kensington, August 9

\section{Electric Clocks}

THE varions contrivances for electric clocks all depend on producing contacts with the pendulum, which is confessedly prosimb and they nearly all produce these contacts when the pendulum is at rest at the highest point, which is the worst position.

There seems no reason why a pendulum with a coil-bob traversing over a short permanent magnet, as is usual, should not be independent of contacts. While descending the lower part of the strolse it reaches the magnet, and a current is thus excited in the coil, which is conveyed out at the knife-edges and works a switch; this sends a battery current through the coil for a short period while the pendulum is beginning its ascent, and so drives it forwards by repulsion from the magnet. The same process is repeated in the back stroke. The interval between the production of the excited current and the battery current, and also the duration of the battery current, may be regulated by a small pendulum whose single swing is equal to the interval, and which is liberated by the cxcited current. The details are so easily 